\title{
Duties and Outcomes
}

\begin{abstract}
The two main traditions in moral philosophy differ in their perspectives on the lengths we can go to in order to maximize the best possible outcome for the people affected by our decisions and actions. Utilitarianism maintains that the morally right option in every situation is the one that will create the best overall outcome for all concerned while duty ethics claims that there are important limitations to what we can do to others, even if the option generates the best overall outcome. It places particular value on respect and human dignity, offering individuals moral protection against treatment as mere means to maximize outcomes. The chapter uses the trolley problem, introduced by Philippa Foot, as a starting point for exploring the differences between utilitarianism and duty ethics in organizational settings. It explains how the Doctrine of Double Effect and the distinction between intended and foreseen consequences allow duty ethics to accept harmful outcomes in some cases.
\end{abstract}

Keywords Duty ethics • Consequentialism • Utilitarianism • Trolley problem

Consequentialism is the view that the morally right thing to do in a given situation is to create the best possible overall outcome for all concerned. The dominant version of this tradition in moral philosophy is utilitarianism, which measures consequences in terms of utility and the extent to

(C) The Author(s) 2019

$\varnothing$. Kvalnes, Moral Reasoning at Work, https://doi.org/10.1007/978-3-030-15191-1_3 
which our choices generate pleasure, pain, or the realization of positive and negative preferences to the people affected by our decisions. Contemporary utilitarianism takes its lead from the classical texts of Jeremy Bentham (1970 [1789]) and John Stuart Mill (2002 [1859/1863]). A utilitarian decision-maker will attempt to maximize the sum of utility for all concerned, and act with the view of promoting the common good. In contrast, the duty ethics tradition developed from the works of Immanuel Kant claims that there are moral considerations more important than creating maximum utility for those we can affect through our conduct (Kant, 1998 [1785]). It proposes that it is never morally right to treat someone as mere means to achieve something, even if that something is the common good and total sum of well-being of others. The difference between the two traditions is that utilitarianism gives priority to outcome (the good) over conduct (the right), while duty ethics places conduct (the right) ahead of outcome (the good).

If Ben in the reference dilemma mentioned in Chap. 2 seeks advice from utilitarianism and duty ethics respectively, he will get different answers. A utilitarian will inquire about the difficulties the employee is causing at the current job, and the likelihood that he will cause more or less trouble if he gets a job in the other organization. Perhaps the potential employer has a better HR department and is better equipped to handle a quarrelsome employee. For a utilitarian, this would count in favor of Ben keeping information to himself, rather than sharing it. If, on the other hand, the other organization is vulnerable and badly staffed to deal with quarrelsome behavior, the utilitarian pendulum would swing toward the honest alternative. For duty ethics, these considerations of alternative outcomes are morally irrelevant. Ben should be honest in the reference situation, no matter what the consequences are, since he has a moral obligation not to lie. To be dishonest toward the person inquiring about the personal qualities of the employee would be disrespectful, in the sense that Ben would be using him as a mere means to get rid of a problem. Human dignity is at stake both for Ben and the person contacting him about the employee, and Ben owes it to both of them to be frank and forthright.

One significant source of tension between utilitarianism and duty ethics is their conflicting views on the moral protection of those affected by our decisions and conduct. One criticism from duty ethics directed toward utilitarianism is that it offers inadequate moral protection to individuals. It does not give sufficient moral weight to respect and human dignity, by approving the use of men, women, and children as mere means to promote 
the common good. Immanuel Kant provided a categorical imperative for analysis and contemplation of conduct, a way of thinking about right and wrong that he considered to be binding for any rational and moral human being, irrespective of cultural background. He expressed this imperative in different ways. The humanity formulation of the imperative addresses the topic of moral protection:

Act so that you treat humanity, whether in your own person or in that of another, always as an end and never as a means only. (Kant, 1998 [1785], p. 429)

Kant does not claim that we should not use other people as means, and would accept that we pay someone to sweep our floor or bring a parcel to the other side of town. What he considers morally forbidden is to use someone solely as means to an end, where the ways we involve them put hindrances on their opportunities to live a meaningful life. A slave-owner uses the slaves as merely as means to an end. If Ben tells lies to get rid of the difficult employee, he is using the other person merely as means to achieve his own goal of creating a more harmonious workplace.

A utilitarian can argue that torture and other horrible acts under some circumstances are not only morally permissible, but also morally required, since they maximize utility. From a duty ethics perspective, conclusions like that expose the absurdity of the utilitarian outlook. The response from utilitarianism is to criticize duty ethics for providing too much moral protection to individuals, generating passivity in situations where lives can be saved, and societies protected. Utilitarianism embraces the concept of dirty hands (Walzer, 1973), or the idea that it is sometimes morally acceptable to perform actions that in and of themselves are horrible, in the name of the greater good for all those affected.

Moral reasoning and justification in organizations can show traces of utilitarianism and duty ethics, even when the protagonists have limited knowledge of the two traditions. Ethical theories tend to capture different kinds of moral intuitions and gut feelings about how one should act under given circumstances. We can explore the issue further, in the light of a fictitious story created by the British philosopher Philippa Foot (1967) It is the famous trolley problem:

You are standing by the side of a track and see a runaway trolley coming towards you at great speed. The trolley brakes have clearly failed. Further 
down the slope you can see that five people are tied down to the track. The train is heading towards them, and it looks a certainty that the will be run over and killed. As it happens, you are placed next to a signal switch. You can send the runaway trolley down a side track by turning the switch. Unfortunately, one person is tied to the track in that direction. That person will be run over and killed if you turn the switch. Your choice is between turning the switch to save five lives and kill one, or doing nothing and letting the five people down the track be killed. All of the six people affected by your decision are innocent victims. They do not deserve to be in this horrible situation. None of them are friends, relatives or acquaintances of you. What should you do? (Foot, 1967, pp. 8-9)

The trolley case can be seen as a real moral dilemma in that you face a choice of either letting five people get killed, or causing one person to get killed. You have a moral reason to save other people's lives, but also a moral reason to respect the life of innocent people, in this case the poor victim who is tied to the side-track. One of these moral reasons will have to give way. It seems that you encounter a choice between doing something wrong and doing something else, which is also wrong.

Foot introduced the trolley problem in a paper where she discussed the moral dimensions of abortion. It has become one of the most eagerly discussed stories in moral philosophy, and has created an entire research tradition that goes under the heading of trolleyology (Edmonds, 2013). We can be skeptical of the practical dimension of the trolley problem, since it describes an artificial situation with few contact points to real life. However, the strength of such a clean cut example is that it is possible to isolate and discuss particular features of moral reasoning. We may not expect to encounter a trolley problem in real life, but the moral intuitions and reflections generated by it are nevertheless relevant for how we respond to less dramatic everyday situations.

When people are presented with the trolley problem, a majority answer that they would have used the switch to put the trolley onto the side-track (Greene et al., 2009). The pattern is the same in my ethics classes for master of science students, where around five hundred students participate annually. Their moral intuitions or gut feelings point them in the direction of doing what it takes to save five lives. Respondents of a utilitarian persuasion claim that it is not a moral dilemma in its purest sense, but rather a situation where it is painful to do the right thing. The outcome of the situation will either be that five or one person dies. The morally right thing to do from a utilitarian perspective is clearly to keep the number of deaths to 
a minimum. If you let the trolley pass and run over the five people down the track, you have done something wrong, in that you have failed to reduce the killings from five to one. According to this line of thinking, then, the choice is between right and wrong. A utilitarian can nevertheless acknowledge that the trolley problem is a moral dilemma in the wider sense, since something of moral value is lost by intervening and causing the death of one innocent person.

Duty ethics can also, to some extent, accept that you use the switch to save five lives. It does so by appeal to the Doctrine of Double Effect (DDE). This ethical doctrine allows a person to cause serious harm to somebody, on the condition that the outcome is not (1) intended by the agent, but only (2) a foreseen consequence. St Thomas Aquinas provided the first formulation of DDE in the thirteenth century, and it has remained an integral part of Catholic ethics ever since. The doctrine can legitimize the use of lethal doses of painkilling medicine for dying patients, where it distinguishes between ( 1 ) the intention to alleviate pain and (2) the foreseen death of the patient. As long as the intention is to kill pain and not to kill the patient, the alternative can be acceptable, according to DDE. The doctrine can also justify instances of abortion where the mother's life is under threat, and the intention is (1) to save the mother's life and (2) an unfortunate, foreseen consequence is the death of the unborn child. Going back to the Trolley problem, DDE can provide moral approval to use the switch since (1) your intention is to save the five, and (2) the unfortunate the death of one is only something you foresee. The ethical logic here is that you are primarily responsible for what you intend, and not for the foreseen, and in this instance, unfortunate effects of your conduct.

In organizations, DDE can provide justification for seriously harming individuals and groups in the name of commercial progress or other business objectives. The leadership of a fishing company in Iceland can decide to close down the fishing plant in a small community, arguing that (1) the intention is to make the organization fit for future market challenges, and that (2) the negative effects on the local community in the form of unemployment is only a foreseen side effect. For this and similar uses of DDE to work, it is a prerequisite that the good outcome in (1) cannot be reached in any other manner than the one also involving (2). The good effect of (1) must also be sufficiently good to compensate for the bad effect in (2). In the Icelandic case, the commercial restructuring of the fishing company to meet future market demands must be sufficiently good to compensate for job-losses and depopulation of rural areas. 
DDE draws what from a utilitarian perspective is an artificial line between intended outcomes and merely foreseen outcomes. The decisionmaker's moral obligation is to maximize utility for all concerned, and whether the consequences are intended or only foreseen side effects is of no significance for a utilitarian.

Judith Jarvis Thomson has discussed a second version of the trolley problem to put pressure on the utilitarian argumentation (Thomson, $1976,1984)$. In this version there is also a runaway trolley hurtling down the track, and five innocent people tied down and facing death if you do not intervene. You are watching the event from a footbridge crossing the track. In front of you stands a fat man. The only way in which you can save the five this time, is by pushing this man down on the track. He will die from the fall, and the weight of his heavy body will suffice to stop the trolley. It is not an alternative to sacrifice yourself and jump ahead of the trolley instead of the fat man, since you are simply not heavy enough. Should you push the fat man?

For the utilitarian the conclusion here is the same as in the first version of the trolley case, since the central equation is the same. It is a matter of simple calculation: one life versus five lives. You should push the fat man in front of the trolley even if you thereby kill him, since that alternative will save five lives. Most people who encounter the experimental circumstances of the second trolley case disagree with this conclusion. Experiments show that people tend to reject the option of pushing the fat man (Cushman, Young, \& Hauser, 2006; Greene et al., 2009). To the utilitarian this is irrational, since the relevant conditions and calculations are the same. All we need to know is that we can influence whether one life or five lives continue.

The alternative account can gather input from duty ethics, and claim that there is a morally relevant difference between the two cases. In the latter case, you would be using the life of one person to save the five. The fat man is an integral part of your plan to save them, while in the former case, the one person on the side-track unfortunately happens to be there. If, by some miracle he had managed to untie himself and get off the track before the trolley arrived, you would welcome that turn of events. If the fat man runs away, it destroys your whole plan. Duty ethics offers moral protection to the fat man. He can hide behind the principle that it is morally forbidden to treat another person as mere means, even if the overall outcome will be better that way. DDE does not come into play here, since by pushing the fat man you would be intending to harm him. His death 
would thus be more than the mere foreseen and unintended side effect of your conduct. Utilitarianism has the frightening feature that everybody can be sacrificed in one way or another, if it serves the purpose of maximizing utility for all concerned.

Neither utilitarianism nor duty ethics would describe the trolley problem as a pure moral dilemma, in the strict sense of presenting choices between two moral reasons, duties and values that are on equal footing. Both traditions would agree that something of moral significance will have to give way when you either choose to prioritize five lives over one, or not. Utilitarianism is not immune to the moral cost of doing something horrible for the greater good. Duty ethics is not immune to the moral cost of letting people die as a result of honoring moral duties. As such, the situation is a real moral dilemma, but both the utilitarian and the duty ethical approaches would describe the cases as choices between right and wrong, and not between wrong and wrong. For a person without a stake in any of the two traditions, the real moral dilemma involves a choice between a utilitarian and a duty ethics response to the problem. The decision-maker can sympathize with both ethical perspectives, but must decide which of them to prioritize.

To what extent are trolley problems 1 and 2 reminiscent of real life challenges? The British politician Gordon Brown was once confronted with the following scenario (Edmonds, 2013, pp. 10-11): You have received information about a tsunami and imminent flood wave, and can rush to alert people in one of two directions. You can go either to the hut where a family of five Thai people lives, or to the hut where one British citizen is staying. There is no time to alert people in both huts, and your intervention will save the lives of those people. Which hut do you run to? Unlike in the trolley cases, the decision-maker does not have an option that will cause death, but must prioritize between one live and five lives. The politician rejected the ethical challenge outright, and said he would use modern technology in the form of a mobile phone to save the people in both huts. From a utilitarian perspective, the correct answer would be to save five lives rather than one, as dictated by the principle of maximizing utility and well-being among those affected by the decision. A duty ethics person would be free to follow any course of action, since none of the alternatives involve being disrespectful in order to save lives. In such neutral circumstances, it seems likely that duty ethics is free to favor the option that generates the best outcome. 
Automation of decision-making processes opens up for ethical challenges that are similar to the trolley problem. How should autonomous vehicles be programmed to behave in situations where they need to prioritize between human lives? In one scenario, the vehicle can either continue straight ahead and kill five pedestrians that have strayed onto the road or turn off the road, an alternative that will lead to the death of the one person inside it. Researchers have discussed the similarities and differences between the trolley problem and various autonomous vehicles scenarios (Bonnefon, Shariff, \& Rahwan, 2016; Gogoll \& Müller, 2017; Nyholm \& Smids, 2016). We will return to the topic in Chap. 8, which is dedicated to automation and ethics more generally.

Moral dilemmas require a response, and something of moral value will be lost, no matter what we decide to do. In this chapter, we have seen that utilitarianism instructs the decision-maker to maximize utility for all those affected by the choice, while duty ethics introduces significant restrictions to how we can reasonably affect other people through our actions. For the former, the end of making the world maximally good can justify the means of sacrificing the lives or well-being of some individuals. The latter provides moral protection for the individual, insisting that we never use others merely as means, no matter how great the overall benefit is. These alternative ethical perspectives can sometimes generate the same conclusions about what we should do, but will often collide and provide opposite normative advice.

\section{REFERENCES}

Bentham, J. (1970 [1789]). An introduction to the principles of morals and legislation. Oxford: Clarendon Press.

Bonnefon, J.-F., Shariff, A., \& Rahwan, I. (2016). The social dilemma of autonomous vehicles. Science, 352(6293), 1573-1576.

Cushman, F., Young, L., \& Hauser, M. (2006). The role of conscious reasoning and intuition in moral judgment: Testing three principles of harm. Psychological Science, 17(12), 1082-1089.

Edmonds, D. (2013). Would you kill the fat man? The trolley problem and what your answer tells us about right and wrong. Princeton, NJ: Princeton University Press.

Foot, P. (1967). The problem of abortion and the doctrine of the double effect. Oxford Review, 5, 5-15.

Gogoll, J., \& Müller, J. F. (2017). Autonomous cars: In favor of a mandatory ethics setting. Science and Engineering Ethics, 23(3), 681-700. 
Greene, J. D., Cushman, F. A., Stewart, L. E., Lowenberg, K., Nystrom, L. E., \& Cohen, J. D. (2009). Pushing moral buttons: The interaction between personal force and intention in moral judgment. Cognition, 111(3), 364-371.

Kant, I. (1998 [1785]). Groundwork of the metaphysics of morals. (M. Gregor Ed.). New York: Cambridge University Press.

Mill, J. S. (2002 [1859/1863]). Utilitarianism and on liberty. Oxford: Blackwell.

Nyholm, S., \& Smids, J. (2016). The ethics of accident-algorithms for self-driving cars: An applied trolley problem? Ethical Theory and Moral Practice, 19(5), $1275-1289$.

Thomson, J. J. (1976). Killing, letting die, and the trolley problem. The Monist, $59(2), 204-217$.

Thomson, J. J. (1984). The trolley problem. Yale Law Journal, 94, 1395-1415.

Walzer, M. (1973). Political action: The problem of dirty hands. Philosophy and Public Affairs, 2(2), 160-180.

Open Access This chapter is licensed under the terms of the Creative Commons Attribution 4.0 International License (http://creativecommons.org/licenses/ by $/ 4.0 /$ ), which permits use, sharing, adaptation, distribution and reproduction in any medium or format, as long as you give appropriate credit to the original author(s) and the source, provide a link to the Creative Commons licence and indicate if changes were made.

The images or other third party material in this chapter are included in the chapter's Creative Commons licence, unless indicated otherwise in a credit line to the material. If material is not included in the chapter's Creative Commons licence and your intended use is not permitted by statutory regulation or exceeds the permitted use, you will need to obtain permission directly from the copyright holder.

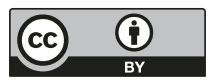

